\section{Compartment syndrome, stiff joints, and diabetic cheiroarthropathy}

Sir: The abnormality in collagen metabolism in diabetes is characterised by unusually stable, excessively cross linked fibrils. Nonenzymatic glycosylation may be partly responsible for the stiffness of diabetic collagen, ${ }^{1}$ and such changes may relate to development of the microvascular complications of nephropathy and retinopathy as well as cheiroarthropathy. Microvascular complications occur more commonly with insulin dependent diabetes mellitus in association with limited joint mobility, changes in skin thickness, and cheiroarthropathy, ${ }^{2}$ suggesting that cheiroarthropathy may be part of a more generalised disorder of collagen metabolism.

We report on a 44 year old woman with insulin dependent diabetes with features of diabetic cheiroarthropathy and stiff joints who presented with exercise induced lower limb pain due to bilateral compartment syndrome. The patient had a four month history of deteriorating, severe, bilateral calf stiffness and pain precipitated by exercise and promptly relieved by rest. She had previously sought an orthopaedic opinion for a stiff left hip and had subsequently been investigated and treated for bilateral shoulder pain and restricted movement. Five years previously she had had impaired movement of the small hand joints.

On examination, the lower limbs were unremarkable and all foot pulses were

Resting and post-exercise tissue pressures $(\mathrm{mmHg})$

\begin{tabular}{lllll}
\hline & \multicolumn{2}{l}{ Compartment } & & \\
\cline { 2 - 5 } & $\begin{array}{l}\text { Right } \\
\text { anterior }\end{array}$ & $\begin{array}{l}\text { Right deep } \\
\text { posterior }\end{array}$ & $\begin{array}{l}\text { Left } \\
\text { anterior }\end{array}$ & $\begin{array}{l}\text { Left deep } \\
\text { posterior }\end{array}$ \\
\hline Resting & 13 & 17 & 17 & 13 \\
Run 1 & 37 & 23 & 31 & 63 \\
Run 2 & 60 & 20 & 54 & 68 \\
Run 3 & 68 & 69 & 55 & 82 \\
Mean exercise pressures & 64 & 22 & 54.5 & $65 \cdot 5$ \\
\hline
\end{tabular}

^The mean of the two closest recordings from three runs. palpable with no vascular bruits. Results of a neurological assessment were normal apart from diminished ankle reflexes. The patient demonstrated a positive 'prayer sign' with flexion deformities of the small hand joints compatible with cheiroarthropathy, and there was a globally reduced range of movement in the shoulders. Blood pressure was normal and fundoscopy showed no evidence of retinopathy. Bilateral compartment syndrome was confirmed by intracompartmental pressure studies. ${ }^{3}$ Anterior compartment syndrome was diagnosed on the basis of exercise pressures exceeding values of $50 \mathrm{mmHg} .{ }^{4}$ The mean of the two closest, stable pressure values after exercise was used for diagnostic purposes (table). A lower threshold value $(40 \mathrm{mmHg})$ was required for deep posterior compartmental syndrome. ${ }^{4}$ The left deep posterior compartment was also abnormal (table), though the pressures in the contralateral compartment did not fulfil the diagnostic criteria (table). Bilateral subcutaneous fasciotomies were performed and by two months after the operation she was able to walk $1500 \mathrm{~m}$ without pain.

Diagnosis of compartment syndrome requires the exclusion of other causes of exercise induced lower limb pain, such as intermittent claudication, spinal stenosis syndrome, tibial stress fracture, superficial peroneal nerve entrapment, medial tibial syndrome, and more simple chronic overuse injuries. ${ }^{5}$ None of these conditions was evident in our patient. Compartment syndrome occurs when tissue pressure exceeds a critical level within a relatively

unyielding osteofascial space, resulting in a compromise in tissue perfusion. An increased incidence has been found in active people, military personnel, and athletes but not, so far as we are aware, in diabetes. In view of the known abnormalities of microvascular flow $^{6}$ and collagen metabolism in diabetes we propose that diabetic patients, particularly those with cheiroarthropathy and stiff joints, may be more susceptible to compartment syndrome. Further study to confirm this association will be required, and we would be interested to hear of other similar cases. As definitive treatment of compartment syndrome with fasciotomy is successful in most patients, this condition should be considered in the differential diagnosis of lower limb pain in patients with diabetes.

$S$ COLEY R D SITUNAYAKE rtment of Rheumatology Department of Rheumatolog Dudley Road Hospital
Birmingham Birmingham
United Kingdom

$M$ J ALLEN

Department of Accident and Emergency Medicine Leicester Royal Infirmary

United Kingdom

Correspondence to: Dr Situnayake.

1 Monnier V M, Vishwanath V, Frank K E, Elmets C A, Dauchot P, Kohn R R. Relation between complications of type I diabetes mellitus and collagen linked fluorescence. $N$ Engl ₹ Med 1986; 314: 403-8.

2 Rosenbloom A L, Silverstein J H, Lezotte D C, Richardson K, McCallum M. Limited joint mobility in childhood diabetes mellitus mobility in childhood diabetes mellitus disease. N Engl f Med 1981; 305: 191-4.

3 Barnes M R, Gibson M J, Scott J, Bentley S, Allen $M \mathrm{~J}$. A technique for the long term measurement of intracompartmental pressure in the lower leg. $\mathcal{F}$ Biomed Eng 1985; 7: 35-9.

4 Allen M J, Barnes M R. Exercise pain in the lower leg. F Bone foint Surg [Br] 1986; 5 818-23.

5 Styf J. Chronic exercise induced pain in the anterior aspect of the lower leg. An overview of diagnosis. Sports Medicine 1989; 7: 331-9.

6 Young J L, Pendergast D R, Steinbach J. Oxygen transport and peripheral microcircu-
lation in long term diabetes. Proc Soc Exp Biol Med 1991; 196: 61-8. 